\title{
Editorial
}

\section{Rise of human devastation syndrome in Syria}

\section{Syed Roshaan Ahmed, Syed Uzair Mahmood*, Haema Waheed}

Jinnah Sindh Medical University, Karachi, Pakistan

\section{*Correspondence:}

Dr. Syed Uzair Mahmood,

E-mail: uzair.hbb@gmail.com

Copyright: ( $)$ the author(s), publisher and licensee Medip Academy. This is an open-access article distributed under the terms of the Creative Commons Attribution Non-Commercial License, which permits unrestricted non-commercial use, distribution, and reproduction in any medium, provided the original work is properly cited.

The Syria civil war, which started in 2011, has killed 400,000 people. ${ }^{1}$ It has forced more than 11 million people to suffer and has caused not only the people to migrate but also to be displaced within their own country. The war has brought only misery in the lives of Syrians as the damage has only focused on residents of the region in combat. The children have faced the worst, losing their parents, siblings or even friends to violence, suffering physical and psychological trauma. Out of the 11 million and more people who have suffered, 4.9 million Syrians are refugees and 6.1 million have displaced within Syria, out of which half of those affected are children. ${ }^{2}$

The end result of the continued Syria Civil War is that those who have managed to survive have been severely damaged both physically and psychologically, disturbing their interpersonal, psychosocial, physical and mental health. The incidence of posttraumatic stress disorder (PTSD) increases in such a situation, which tends to affect the lives of the Syrian people permanently. ${ }^{3}$

\section{WHAT IS POST TRAUMATIC STRESS DISORDER?}

Posttraumatic stress disorder (PTSD) as defined by diagnostic and statistical manual of mental disorders (DSM) stems from an event which posed a serious threat to the life of an individual that caused the individual to experience feelings of helplessness, fear or horror. ${ }^{4}$

\section{RISK FACTORS}

PTSD is associated with certain risk factors that can be divided into three categories namely; factors that was present before the traumatic event, the traumatic event itself and post traumatic factors.
The pre exposure risk factors would include age, gender, race, genetic susceptibility and lastly prior life adversaries. Out of each of the listed pre exposure risk factors the one with the highest association is prior life adversaries and it is seen that individuals exposed to traumatic events over a period of time are at greater risk of developing PTSD. ${ }^{5}$ Since people of Syria are exposed to traumatic events very frequently, which maybe in the form of blast/explosive crisis or being starved for food, or being the pressure for child marriages, or even watching your parents die in front of your own eyes, makes this factor very significant their case.

The type and severity of the traumatic event itself is highly associated with the development of PTSD. Another association found includes perceived life threat, which in case of people of Syria becomes a significant factor as they are well aware of the risks and threats associated with living in their country each and every day and this increases the risk of development of PTSD in such individuals.

In the post trauma exposure risk factors, social support plays an important role as it reduces the risk of developing PTSD in an individual. However, since the people of Syria, majority of them have lost their parents, siblings, children or even friends this increases the risk of development of PTSD in such groups.

\section{PATHOPHYSIOLOGY OF PTSD}

The development of PTSD requires an alteration in the hypothalamic-pituitary-adrenal axis. Epinephrine and norepinephrine, secreted by the adrenals are stress related hormones. They are responsible for the fight and flight response seen with stressful situations. Abnormalities in the locus coeruleus (LC) have been identified, which link the stress hormone epinephrine with the development of 
PTSD. Normally, norepinephrine at physiological level, acts at the level of the genes, even memory regulates the selection of appropriate rapid response to the stimuli. However, prolonged and extreme activation of LC and release of norepinephrine results in symptoms of excessive sensitivity of arousal, memory and results in the development of responses or activation of LC to even innocuous stimuli. Since the people of Syria have been exposed to stressful situations for a prolonged time, they develop abnormalities in their LC functioning leading to the development of PTSD. ${ }^{5}$

\section{PROGRESS FROM PTSD TO HUMAN DEVASTATION SYNDROME}

Given that the survivors of the war, which are mostly Syrian children, have faced greater trauma as compared to a usual individual who suffers from PTSD, Dr. M.K Hamza, a neuropsychologist with the Syrian American Medical Society (SAMS) described the condition suffered by the survivors as human devastation syndrome (HDS) on 18 February 2017. HDS basically describes the severity of symptoms of PTSD that the people suffer. ${ }^{6}$

\section{CLINICAL SIGNIFICANCE OF PTSD AND HDS CRITERIA}

For a diagnosis of PTSD, the symptoms of severe anxiety should last greater than 1 month along with the impairment of the normal functioning of an individual. If the symptoms have persisted less than 3 months then a diagnosis of acute PTSD is given. If the symptoms persist more than 3 months then a diagnosis of chronic PTSD is given.

PTSD is defined by three cluster symptoms as outlined by DSM. The First cluster of symptoms involves reliving or re-experiencing some or all of the traumatic events through vivid dreams, flashbacks or intrusive recollections. The Second cluster involves avoidance of stimuli associated with trauma, including people, places or even thinking about the incident. The Third cluster involves hyperarousal symptoms such as impaired memory, impaired concentration, exaggerated startled response and hypervigilance. Clinically such individuals are more prone to develop other mental disorders such as depression and other anxiety disorders. While the diagnosis of PTSD is based clinically entirely on thorough history, collateral sources and reviewing medical records there are certain structured diagnostic interviews to help assess and diagnose a suspected individual suffering from PTSD. Out of a large number of structured diagnostic interviews, the one considered gold standard is Clinician Administered PTSD Scale (CAPS) but due to the limitation of time other self-report questionnaires can also be used including PTSD checklist. $^{7}$

The term human devastation syndrome has exclusively been reserved for the Syrian refugees as they have suffered, sighted or experienced things that individuals in other countries of the world haven't. It describes the severity of PTSD and the emotional impact on the individual. It indicates the urgency to stop the misery faced by the Syrian people and to come up with management plans to keep those Syrian survivors from functioning properly in the society. HDS describes the need to come up with better treatment options for the severity of the symptoms faced by the Syrian people. ${ }^{2}$

\section{INCIDENCE}

According to a study conducted in 2014, 50-57 percent of Syrian refugees suffer from PTSD. Between 3-30 percent of them suffer from depression (EMPHNET 2014).

\section{MANAGEMENT}

While it can be seen clearly the great increase in the number of Syrian refugees suffering from PTSD, most of the refugees (approximately 41 percent) do nothing for their mental condition. While 58 percent are involved in doing something for their mental condition, which includes socializing (15\%), praying and reading Quran $(13 \%)$, fighting and getting angry $(11 \%)$, crying $(6 \%)$, walking $(5 \%)$, sleeping $(5 \%)$ and smoking $(5 \%)$. [EMPHNET, 2014]. ${ }^{8}$

The management options for PTSD and HDS include psychotherapy and pharmacotherapy. While psychotherapy has been proven to be more effective than pharmacotherapy, management results are better if the two are combined together. ${ }^{9}$ Among the psychotherapies offered, Trauma Focused Cognitive Behavioral Therapy (TFCBT) and Eye Movement Desensitization and Reprocessing (EMDR) have been evaluated as being the most effective. TFCBT being slightly more effective than EMDR. ${ }^{10}$ Among the pharmacotherapies, selective serotonin reuptake inhibitors (SSRIs) have been shown to be the most effective. They are considered the first line agents for the treatment of PTSD because of favorable adverse effect profile. If they fail, the second line agents including serotonin potentiating non SSRIs are considered. They also have a good safety profile. Lastly if the two lines of agents fail to improve the condition of the patient a trial of tricyclic antidepressants, mono amine oxidase inhibitors (MAOI) and anticonvulsants should be tried. ${ }^{11}$

While these therapies aim at reducing the symptoms of PTSD, the only definitive management would be to prevent it from happening which is only possible if the Syria civil war is put to an end.

\section{IMPORTANCE AND SIGNIFICANCE}

It becomes important to recognize the severity of the emotional and mental problems faced by the Syrian people and it becomes even more important to come up with strategies to heal and help the people who manage to 
survive the cold war. It becomes important to understand the severity of the conditions faced by the Syrian people and to help end their misery. While there seems no way to end the civil war, the only way Syrians refugees can be helped is by emotional support and management aimed at relieving their symptoms so that they can function normally in the society.

Funding: No funding sources

Conflict of interest: None declared

Ethical approval: Not required

\section{REFERENCES}

1. Avaialble at: http://www.aljazeera.com/news/2016/ 04/staffan-de-mistura-400000-killed-syria-civil-war160423055735629.html. Accessed on 8th March 2017.

2. Available at: https://www.worldvision.org/refugeesnews-stories/syria-refugee-crisis-war-facts. Accessed on 8th March 2017.

3. Alpak G, Unal A, Bulbul F, Sagaltici E, Bez Y, Altindag A, et al. Post-traumatic stress disorder among Syrian refugees in Turkey: a cross-sectional study. International journal of psychiatry in clinical practice. $2015 ; 19(1): 45-50$.

4. Available at: http://www.brainlinemilitary.org/ content/2014/06/dsm-v-tr-criteria-for-ptsd.html.

Accessed on 8th March 2017.
5. Shiromani P, Keane TM, LeDoux JE. Posttraumatic stress disorder. Humana; 2014.

6. Available at: http://www.attn.com/stories/15150/ doctors-new-term-describe-syrian-childrenssuffering. Accessed on 8th March 2017.

7. Hunsley J, Mash E. A guide to assessments that work. 1st ed. New York: Oxford University Press; 2008.

8. Available at: https://www.apa.org/international/pi /2015/09/noor-baker.pdf. Accessed on 8th March 2017.

9. Van Etten ML, Taylor S. Comparative efficacy of treatments for post-traumatic stress disorder: a metaanalysis, 1998.

10. Bisson JI, Ehlers A, Matthews R, Pilling S, Richards D, Turner S. Psychological treatments for chronic post-traumatic stress disorder. The British journal of psychiatry. 2007;190(2):97-104.

11. Asnis GM, Kohn SR, Henderson M, Brown NL. SSRIs versus non-SSRIs in post-traumatic stress disorder. Drugs. 2004;64(4):383-404.

Cite this article as: Ahmed SR, Mahmood SU, Waheed H. Rise of human devastation syndrome in Syria. Int J Community Med Public Health 2018;5:1227-9. 